\title{
Resenha do livro Catálogos de paisajes de Andalucía: catálogo de paisajes de la provincia de Sevilla
} \author{
catálogo de paisajes de la provincia de Sevilla

\section{Luciene CRistina Risso ${ }^{a}$} \\ ${ }^{\text {a }}$ Profa. Dra. em Geografia. \\ E-mail: Luciene@ourinhos.unesp.br
}

Review of the book Catálogos de paisajes de Andalucía:

\begin{abstract}
NARANJO, F. Z.; RODRIGUEZ, J. R. (Org.). Catálogos de paisajes de Andalucía: catálogo de paisajes de la província de Sevilla. Sevilla: Centro de Estudios Paisaje y Territorio, 2014.
\end{abstract}

A Espanha, antes mesmo de a Convenção Europeia da Paisagem (CEP) entrar em vigor em 2008, já tinha uma política legal de proteção e valoração de paisagens. É o caso da comunidade da Andaluzia, pioneira no assunto. Todavia, com a CEP, houve um desenvolvimento significativo da temática e a produção de muitas publicações de atlas, catálogos e mapas de paisagens.

Para a CEP, paisagem é "cualquier parte del territorio tal como lo percibe la población, cuyo carácter sea el resultado de la acción y la interacción de factores naturales y/o humanos". Uma das recomendações da Convenção é o conhecimento das paisagens, melhorar o sistema político de proteção das paisagens europeias com sistema de indicadores de qualidade e os atributos valorados pela sociedade. Para isso, os estados-membros estudam terminologias e metodologias específicas comuns, como a prestigiada metodologia britânica da landscape character assessment (LCA).

Esse livro/catálogo apresenta uma sistematização do conhecimento das paisagens de Andaluzia, mais precisamente da província de Sevilla ${ }^{1}$ (Figura 1), realizada pelo Centro de Estudos de Paisagem e Território da região, seguindo as recomendações da CEP.

O Centro de Estudos de Paisagem e Território é um centro que realiza projetos de excelência científica

1 Além de Sevilla, há a publicação das províncias de Málaga e Granada. da Junta de Andaluzia, unindo pesquisadores, docentes de diversas universidades da comunidade autônoma da região (Figura 2) em competências de paisagem e ordenamento territorial. Atualmente o diretor do Centro é o doutor Florencio Zoido Naranjo, que gentilmente cedeu o livro impresso durante minha estadia para o meu pós-doutorado na Universidade de Sevilla.

Figura 1: Capa do livro resenhado.

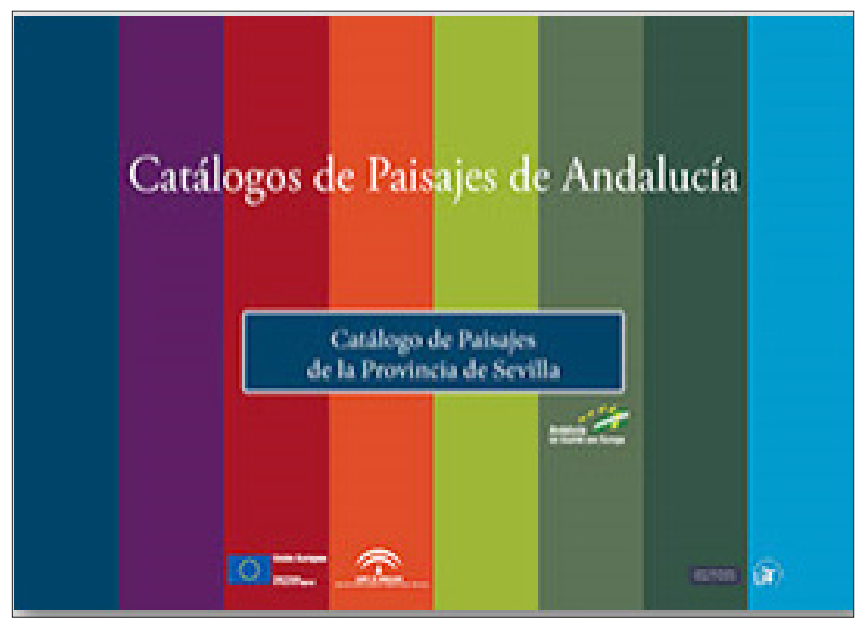

Fonte: $<$ http://bit.ly/2ubbfOg>.

O livro está assim estruturado:

O Capítulo 1 engloba marcos legais e antecedentes; enfoque conceitual e metodológico; orientação e procedimentos metodológicos, e conteúdos básicos de um catálogo de paisagens. 
Figura 2: Parceiros do Centro de Estudos de Paisagem e Território.

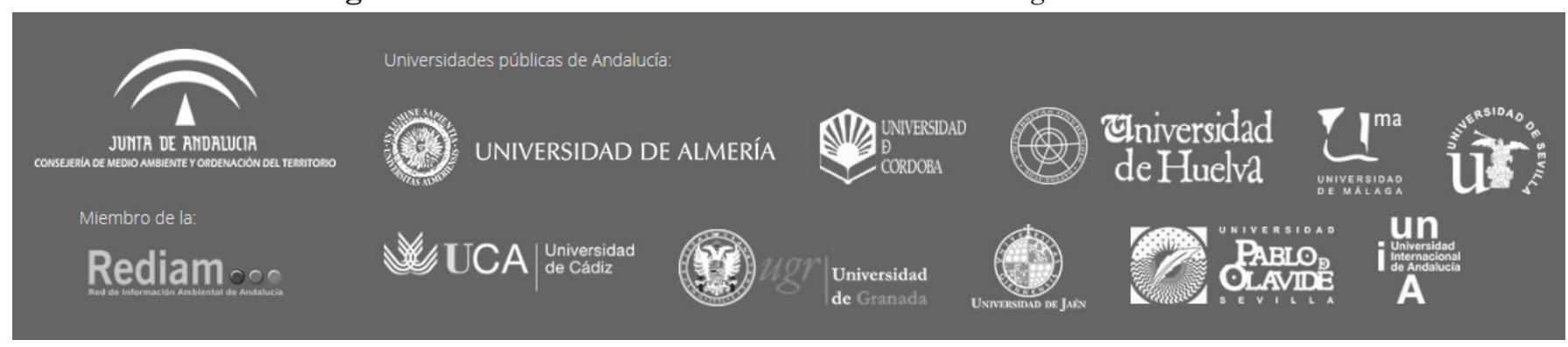

Fonte: <http://bit.ly/2vzPfwu>.

O Capítulo 2, intitulado "Fundamentos naturais e culturais da paisagem", integra os fundamentos e componentes naturais da paisagem, o processo de construção histórica do território, as percepções, representações e valores consolidados, bem como as dinâmicas e processos. Esse capítulo é bem interessante por ter uma visão integrada da paisagem, unindo o natural e o cultural.

O Capítulo 3, "A diversidade paisagística provincial: âmbitos, tipos e áreas paisagísticas", mostra a classificação e as tipologias gerais das paisagens da província de Sevilla.

A metodologia do Centro afirma que "a partir de um mapa geomorfológico, um mapa de uso e cobertura vegetal e imagens de satélite, identificam-se grandes categorias de paisagem. As áreas cênicas são o resultado da subdivisão dessas categorias" ${ }^{\text {.2 }}$. As categorias paisagísticas de Andaluzia são divididas em altiplanos e subdesertos estepários, campinas, litoral, serranias, vales, vegas e marismas (Figura 3).

As áreas de paisagem, de acordo com o livro, são as "áreas que contam com uma identidade territorial e paisagística inconfundível, única e facilmente reconhecível para a população. Sua singularidade se relacionada geralmente com as questões mais intangíveis da paisagem" (p. 7).

De acordo com a dominante funcional e perceptiva nas diferentes áreas territoriais da província, o centro propôs uma classificação inicial significativa dos tipos de paisagem, com base no contexto geral em que estão inseridos e na agregação de usos e aproveitamento do solo:

- Paisagens de dominante agrária;

- Paisagens de dominante natural;

- Paisagens de dominante geológica;

- Paisagens construídas ou alteradas.

2 Informação do mapa: <http://bit.ly/2huIaHB>.
O Capítulo 4 caracteriza e qualifica as paisagens da província de Sevilla. Por fim, o Capítulo 5 fala dos objetivos, critérios e recomendações para a integração da paisagem.

Desse modo, o livro é um importante referencial para as pesquisas da paisagem de Sevilla, além de ser um modelo para os estudos de paisagem no Brasil. O livro pode ser baixado gratuitamente no site do Centro de Estudos da Paisagem e Território: <http:/ / bit.ly/2ubbfOg $>$.

Figura 3: Mapa das categorias paisagísticas de Andaluzia - Espanha

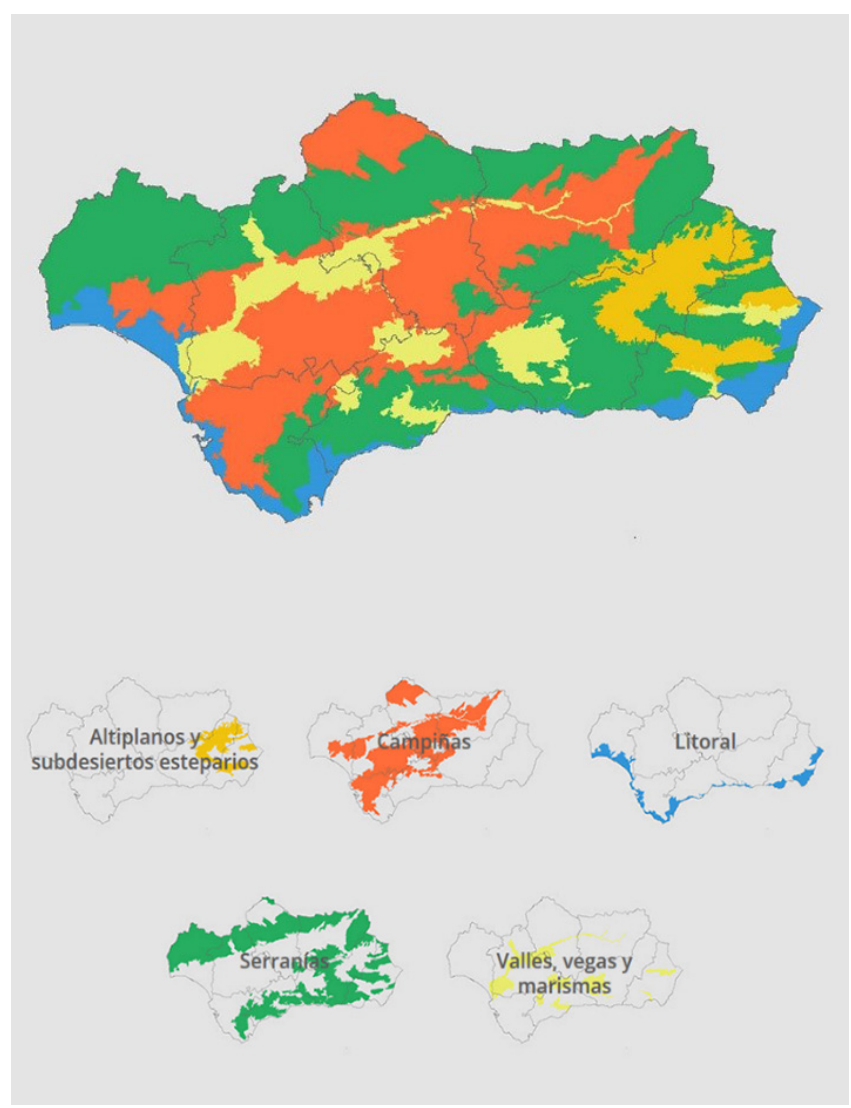

Fonte: Centro de Estudios de Paisaje y Territorio. Disponível em: <http://bit.ly/2ur2lHn>. 